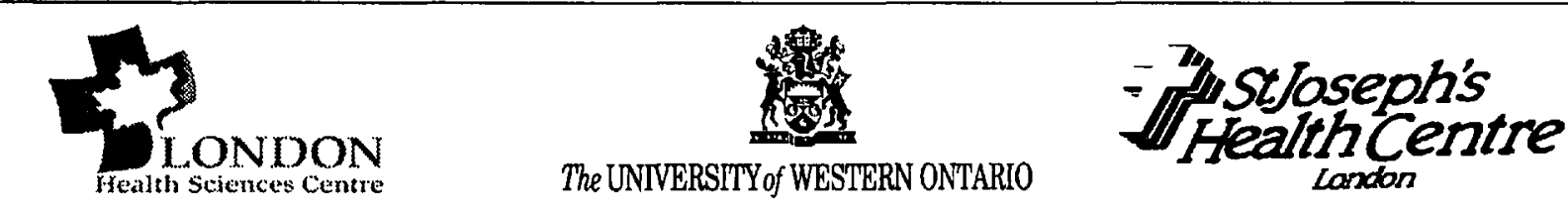

\title{
FELLOWSHIPS AVAILABLE
}

FELLOWSHIPS at the LONDON HEALTH SCIENCES CENTRE and ST. JOSEPH'S HEALTH CENTRE are available for January 1, 1998 and July 1, 1998 in subspecialty areas or as a blend of the subspecialties.

CARDIAC ANAESTHESIA: Over 1,500 pump cases yearly for coronary, valvular, arrhythmia and transplantation surgery.

VASCULAR \& THORACIC ANAESTHESIA: Over 600 cases per year for pulmonary, oesophageal and aortofemoral surgery.

NEUROSURGICAL ANAESTHESIA: Over 2,000 cases yearly of which a large proportion are for cerebral vascular or epilepsy surgery.

TRANSPLANTATION: The multi-Organ Transplant Service performs heart, heart/lung, liver and kidney transplants.

AMBULATORY CARE: Over 9,000 cases yearly for a variety of surgical procedures.

PAIN MANAGEMENT: The Acute Pain Service cares for over 4,000 patients per year while the Chronic/Outpatient Pain Service handles over 2,500 visits per year. Paediatrics and community based care can be included.

OBSTETRIC ANAESTHESIA: There are approximately 4,500 deliveries per annum. St. Joseph's Health Centre is the tertiary high-risk referral centre for the Southwestern Ontario region.

REGIONAL ANAESTHESIA: Over 1,200 cases are done under regional anaesthesia including continuous catheter blocks, spinals and epidurals.

RESEARCH opportunities exist in all areas.

London is a pleasant University City less than two hours drive from Toronto and Detroit.

Candidates must be eligible for Canadian Fellowship in Anaesthesia or American Board Certification or be eligible for Ontario licensing.

Send curriculum vitae and an outline of special interests to:

\section{Adrian W. Gelb, MB, ChB, FRCPC, Professor and Chair, Department of Anaesthesia London Health Sciences Centre, 339 Windermere Road, London, Ontario, CANADA N6A 5A5 Telephone: 519-663-3270 Fax: 519-663-3079 Email: agelb@julian.uwo.ca}

\section{INDEX TO ADVERTISERS}

Astra Pharma Inc.

(PAGE)

VIII, IX

Organon

Wellcome Medical Division/

Glaxo Wellcome Inc.

Zeneca Pharma
OUTSIDE BACK COVER

INSIDE FRONT COVER

... II
PRESCRIBING INFO. (PAGE)

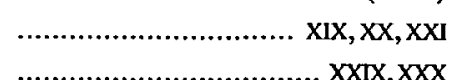

$X X I I, X X I I I, X X I V, X X V$ $\mathrm{XXV}, \mathrm{XXVII}$

\section{CLASSIFIEDADVERTISING}

Canadian Anaesthetists' Society. IV, VI, X, XI, XII, XIII, XIV, INSIDE BACK COVER Classified Advertising and Meetings . XVII,XVII

Hamilton Health Sciences Corporation ... XXXII

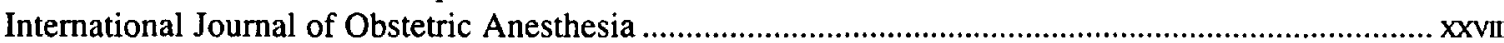

Kingston General Hospital .... XXXIII

London Health Sciences Centre XXXII, XXXIV

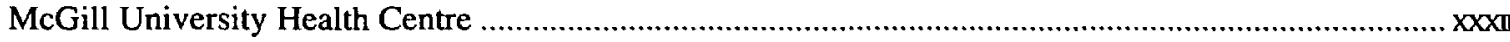

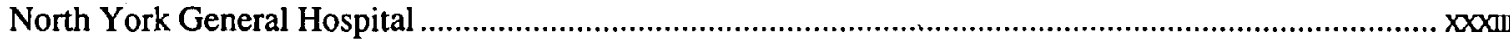

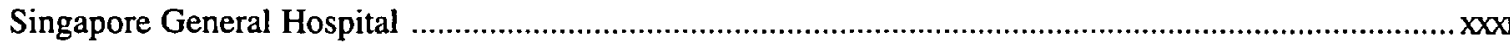

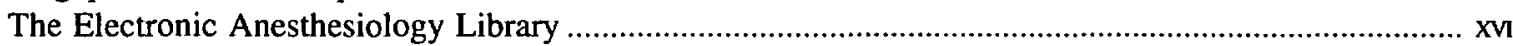

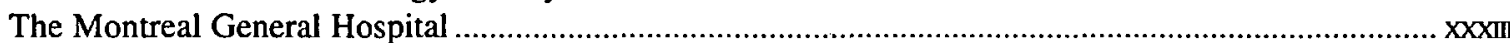

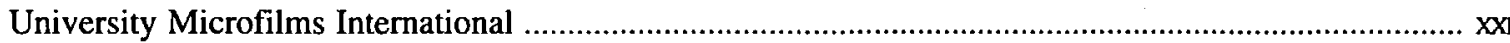

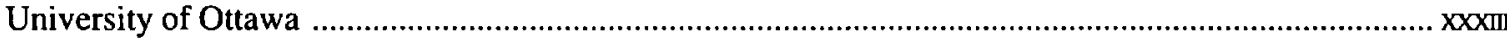

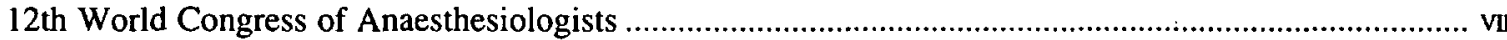

